Check for updates

Cite this: RSC Adv., 2019, 9, 25170

Received 15th June 2019

Accepted 30th July 2019

DOI: 10.1039/c9ra04499j

rsc.li/rsc-advances

\section{Ligand geometry controlling Zn-MOF partial structures for their catalytic performance in Knoevenagel condensation $\uparrow$}

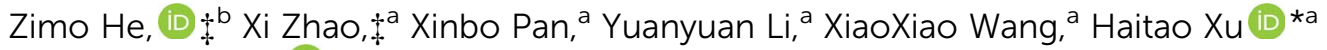 \\ and Zhenliang $\mathrm{Xu}\left(\mathrm{DD}^{\mathrm{a}}\right.$ \\ A series of novel Zn-MOFs \{1Zn: [Zn(NIA $\left.)_{2}(3-b p d h)_{2}\right] ; 2 Z n: \quad\left[Z n(N P A)_{2}(4-b p d h)_{2} \mathrm{H}_{2} \mathrm{O}\right.$ ]; 3Zn: \\ $\left.\left[\mathrm{Zn}_{2}(\mathrm{CHDA})_{4}(3-\mathrm{bpd})_{2}\right]\right\}$ were constructed by dicarboxylic acid and $\mathrm{N}, \mathrm{N}^{\prime}$-bis(pyridine-yl-ethylidene) \\ hydrazine. Ligand geometry revealed 1D to 3D Zn-MOF crystal topologies, whose combined-mode \\ could be affected by the conditions. All these conditions affected the micro-nano crystal \\ morphologies, namely $1 \mathrm{Zn}$ micro-sheets or nanospheres, $2 \mathrm{Zn}$ micro-clusters or micro-stick, and \\ $3 Z n$ micro-clusters or hollowspheres that were obtained. The catalysts exhibited $100 \%$ selectivity for \\ Knoevenagel condensation reactions, among which the benzaldehyde conversion rate of the $3 \mathrm{Zn}$ \\ hollowspheres was the highest, reaching a peak of $90 \%$.
}

Metal-organic frameworks (MOFs) are a kind of rigid skeletal crystal formed via the coordination of metal ions with organic ligands, characterized by a large specific surface area, high porosity and structural diversity. ${ }^{1-3}$ The abundance of metal atoms and organic ligands led to diverse and intriguing assemblies. ${ }^{4}$ Since the pioneering work of Yaghi et al. ${ }^{5-7}$, more than 20000 MOFs have been reported and have shown remarkable prospects in many applications, such as adsorption, ${ }^{8-11}$ electrochemistry, ${ }^{12-14}$ catalysis $^{15-17}$ and luminescence, ${ }^{\mathbf{1 8 - 2 0}}$ among which the research on catalysis is one of the rapidly growing applications. The inherent properties of MOFs make them excellent catalysts: these properties include highly dense active sites and even dispersion in the skeletons of MOFs, while their porosity facilitates the transport and diffusion of reactants, facilitating easy contact with those active sites. ${ }^{21}$

The Knoevenagel condensation is a classic reaction, which provides an effective way to form $\mathrm{C}-\mathrm{C}$ double bonds by the reaction of carbonyl compounds, such as aldehydes or ketones, with compounds containing active methylene groups. It has been widely used in the synthesis of many compounds and is a reaction with an important application

${ }^{a}$ State Key Laboratory of Chemical Engineering, Membrane Science and Engineering $R \& D$ Lab, Chemical Engineering Research Center, East China University of Science and Technology (ECUST), 130 Meilong Road, Shanghai 200237, China. E-mail: xuhaitao@ecust.edu.cn

${ }^{b}$ School of Chemistry and Molecular Engineering, East China University of Science and Technology (ECUST), 130 Meilong Road, Shanghai 200237, China

$\dagger$ Electronic supplementary information (ESI) available. CCDC 1916894-1916896. For ESI and crystallographic data in CIF or other electronic format see DOI: 10.1039/c9ra04499j

\$ Zimo He and Xi Zhao contributed equally to this study. value in organic synthesis. ${ }^{22-26}$ In recent years, many catalysts for such reactions have emerged, ${ }^{27-29}$ among which MOFs or MOF-derived solid bases have shown remarkable catalytic performance..$^{30-33}$

In this study, we prepared three new MOFs with onedimensional, two-dimensional and three-dimensional structures. First, by combining zinc 5-nitroisophthalic acid (NIA) with $N, N^{\prime}$-bis(1-pyridine-3-yl-ethylidene)hydrazine (3bpdh) (1Zn); second, by combining zinc 3-nitrophthalic acid (NPA) with $N, N^{\prime}$-bis(1-pyridine-4-yl-ethylidene)hydrazine (4bpdh) (2Zn); and third, by combining zinc 1,4-cyclohexanedicarboxylic acid (CHDA) with $N, N^{\prime}$-bis(1-pyridine-3yl-ethylidene) (3-bpd) (3Zn). By changing the reaction conditions, 1Zn nanospheres, 2Zn microsticks and 3Zn hollowspheres were obtained. We also investigated the catalytic performance of the six catalysts for Knoevenagel condensation and analyzed the possible catalytic mechanism.

As shown in Fig. 1, the zinc atoms in all three crystals are present in a hexacoordinate environment; however, the coordination direction can be influenced by different ligands coordinated with zinc atoms, so as to obtain three kinds of MOFs with one-dimensional, two-dimensional and threedimensional structures. 1Zn crystallized in a triclinic space group $P \overline{1}(2)[a=8.585(5) \AA, b=10.181(6) \AA, c=14.860(12) \AA$, $\alpha=104.46(9)^{\circ}, \beta=101.00(9)^{\circ}, \gamma=102.35(6)^{\circ}, \quad V=$ 1186.92(140) $\left.\AA^{3}, Z=2\right]$. The Zn(II) center was bonded to four $\mathrm{O}$ atoms from the carboxylate groups of two 5-nitrophthalic acid ligands and two $\mathrm{N}$ atoms from the 3-bpdh ligand, forming $\mathrm{ZnO}_{4} \mathrm{~N}_{2}$ metal nodes. Two 3-bpdh ligands linked two $\mathrm{ZnO}_{4} \mathrm{~N}_{2}$ metal nodes to form ring structures, and each ring 


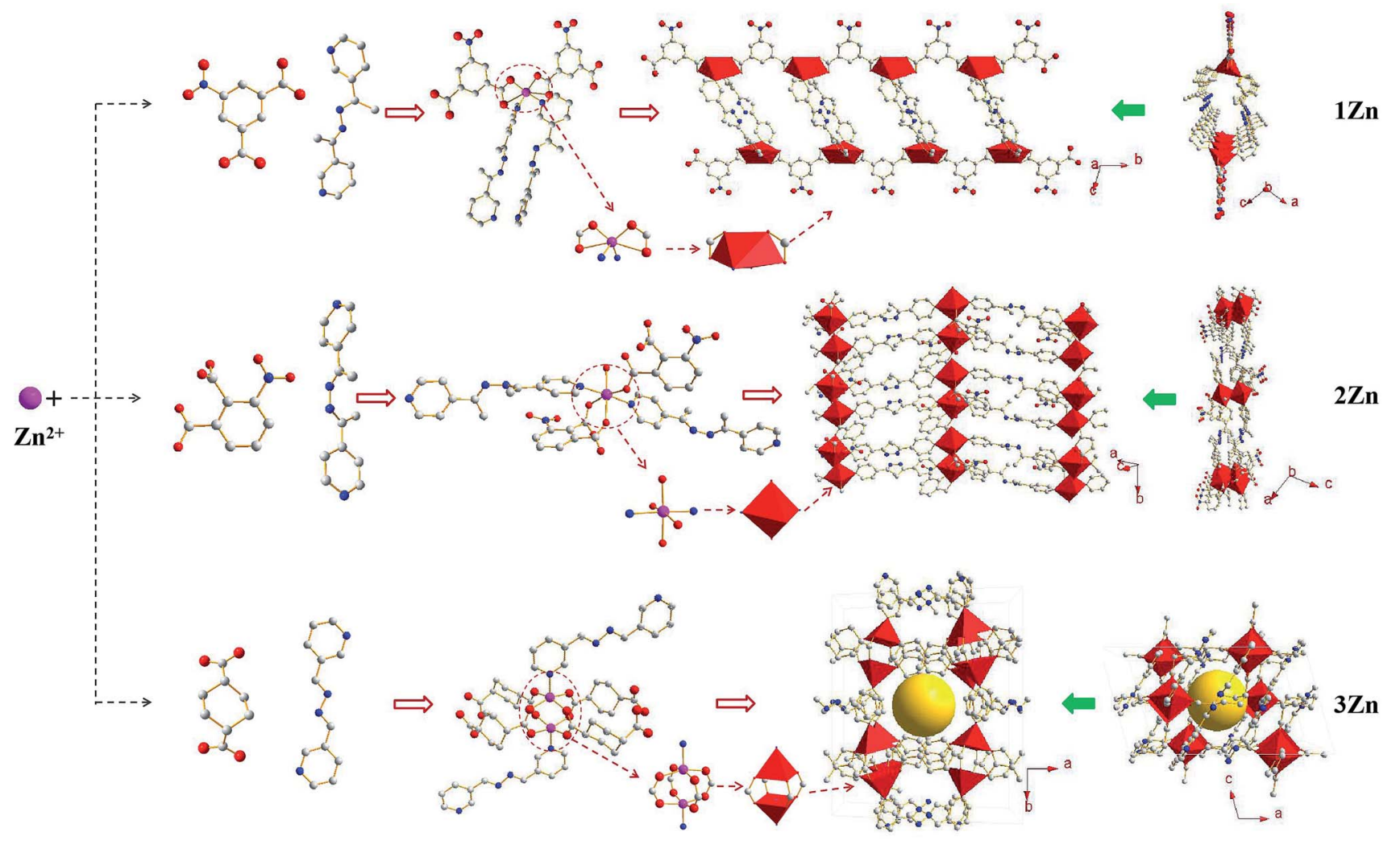

Fig. 1 Molecular structure of 1Zn, 2Zn, 3Zn.

was connected by 5 -nitrophthalic acid molecules. The single coordination direction determines the one-dimensional (1D) tube structure of the crystal. 2Zn crystallized in a monoclinic space group $P 12_{1} / c_{1}(14)[a=14.74(3) \AA, b=8.444(15) \AA, c=$ 19.15(3) $\left.\AA, \beta=106.96(17)^{\circ}, V=2279.87(700) \AA^{3}, Z=4\right]$. The $\mathrm{Zn}$ (II) center was bonded to three $\mathrm{O}$ atoms from the carboxylate groups of two 3-nitrophthalic acid ligands, two $\mathrm{N}$ atoms from the 4-bpdh ligand, and one $\mathrm{O}$ atom from $\mathrm{H}_{2} \mathrm{O}$, forming $\mathrm{ZnO}_{4} \mathrm{~N}_{2}$ metal nodes. In this metal node, the carboxyl group had two coordination modes: the $\mathrm{O}$ atoms from No.1 and No.2 carboxyls in one 3-nitrophthalic acid chelated the $\mathrm{Zn}$ (II) center to form 7-member ring, while the $\mathrm{O}$ atom from the No.1 carboxyl in the other 3-nitrophthalic acid bridged this $\mathrm{Zn}$ (II) center to other $\mathrm{ZnO}_{4} \mathrm{~N}_{2}$ metal nodes. The 4-bpdh ligand and 3-nitrophthalic acid ligands formed a double chain with a $\mathrm{ZnO}_{4} \mathrm{~N}_{2}$ metal node as the center. The coordination method of $2 \mathrm{Zn}$ is limited to a two-dimensional (2D) plane, resulting in its $2 \mathrm{D}$ structure. $3 \mathrm{Zn}$ crystallized in a monoclinic space group $C_{1} 2 / c_{1}(15)[a=17.23(3) \AA, b=19.96(3) \AA, c=9.432(15)$ $\left.\AA, \beta=105.71(18)^{\circ}, V=3122.62(800) \AA^{3}, Z=8\right]$. Two Zn(II) centers were bonded to eight $\mathrm{O}$ atoms from the carboxylate groups of four 1,4-cyclohexanedicarboxylic acid (CHDA) ligands and two $\mathrm{N}$ atoms from the 3-bpd ligand, forming $\mathrm{Zn}_{2} \mathrm{O}_{4} \mathrm{~N}_{2}$ metal nodes. Four CHDA ligands formed a cross double chain with two zinc atoms as the center, and the 3bpd ligand linked the double chains to yield a three- dimensional (3D) framework. More detailed information about the crystal structure is contained in the ESI. $\dagger$

These three kinds of microcrystals were prepared in methanol and water at room temperature. As shown in Fig. 2, the three kinds of MOFs have different morphologies. Under SEM, 1Zn presents a sheet structure, while $2 Z n$ and $3 Z n$ show flower-like morphologies, which are formed by the secondary assembly of tiny crystals. They are about 10 to 20 microns in diameter, and $\mathbf{3 Z n}$ is slightly larger than $\mathbf{2 Z n}$. The PXRD patterns of the three crystals coincide with the simulated curves of their single crystal, which proves the existence of the respective crystal phases (Fig. S1-S3†).

On this basis, we used different conditions to change the morphologies of these three crystals, which exhibited three improved morphologies (Fig. 3). More conditions were attempted, and the results are shown in the ESI. $\dagger$ A 1 Zn nanosphere was synthesized in a DMF system with the introduction of PVP by a solvent thermal method. PVP is an amphiphilic surfactant, which can adsorb on the surface of nanocrystals and change the growth direction and speed of the crystals, thus affecting the final morphology and particle size of the product. ${ }^{34}$ With the increase in the PVP dosage, the size of the 1Zn nanosphere was smaller and more uniform (Fig. S10†). At $0.1 \mathrm{~g}$ PVP dosage, nanospheres with particle sizes of about $300 \mathrm{~nm}$ were obtained. A $2 \mathrm{Zn}$ microstick was also synthesized by the solvent thermal method in $\mathrm{MeOH}$ solvent. Interestingly, we added sodium acetate as a regulator 

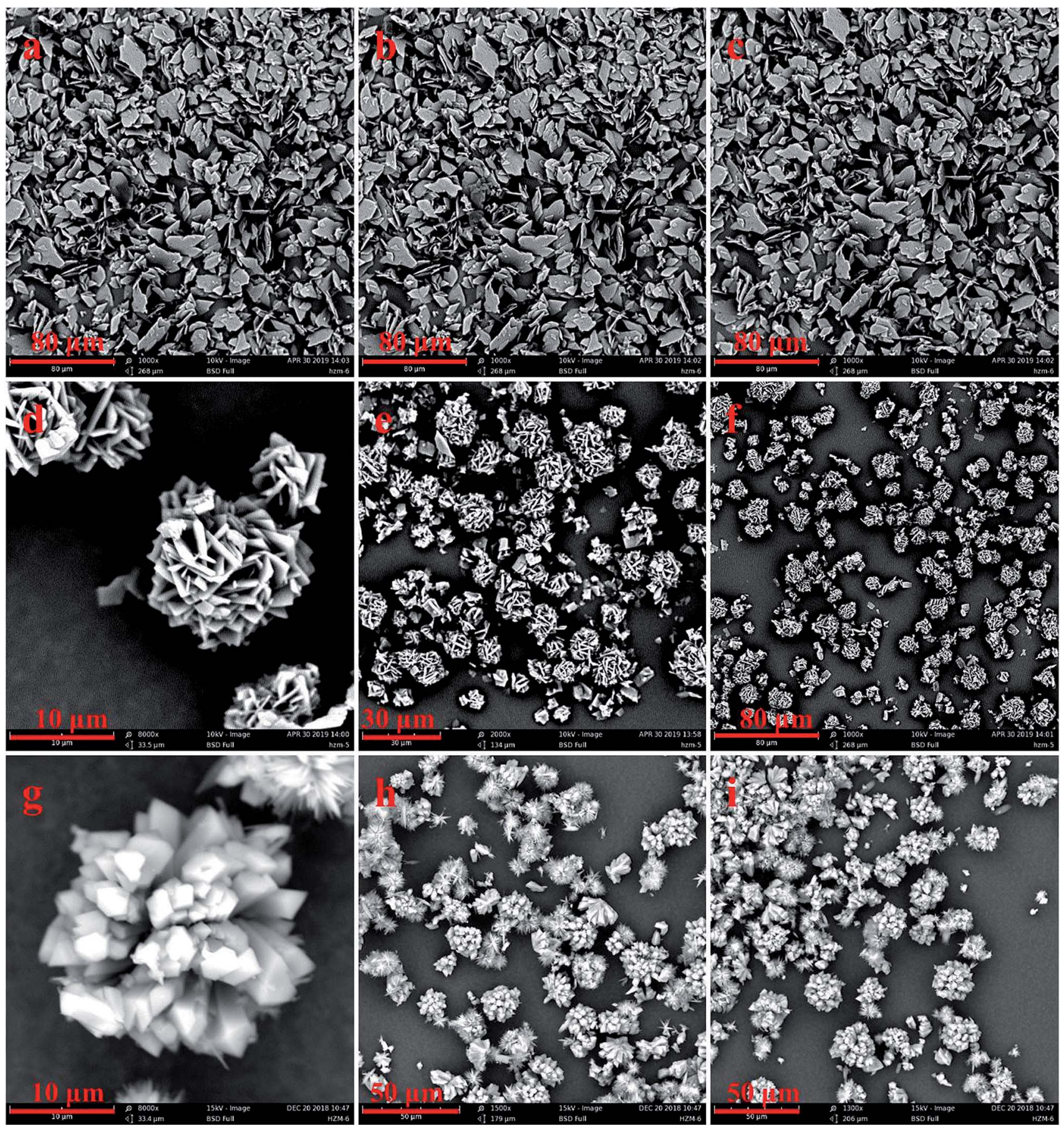

Fig. 2 SEM images of $(a-c) 1 Z n ;(d-f) 2 Z n$; $(g-i) 3 Z n$.

to the DMF system and obtained 3Zn hollowspheres with the assistance of ultrasound. When the dosage of sodium acetate was $0.05 \mathrm{mmol}$, a dandelion-like $3 \mathrm{Zn}$ spherical crystal reassembled by needle crystals was obtained. On continuously increasing the amount of sodium acetate to $0.1 \mathrm{mmol}$, the spherical crystals became hollow. However, when sodium acetate was added to $0.2 \mathrm{mmol}$, the morphology of the product appeared chaotic (Fig. S11 $\dagger$ ). As a base, sodium acetate can accelerate the deprotonation process of carboxylic acid ligands, thus accelerating the growth rate of the crystals. Moreover, there was competitive coordination between $\mathrm{COO}^{-}$and the carboxylic acid ligands, so the introduction of sodium acetate can affect the growth process of the crystals. ${ }^{35}$

The catalytic properties of the catalysts for the Knoevenagel condensation reactions were investigated. As shown in Fig. 4, when the $\mathbf{1 Z n}$ and $\mathbf{2 Z n}$ microcrystals were used as catalysts, the conversions are $64 \%$ and $76 \%$ after 4 hours 

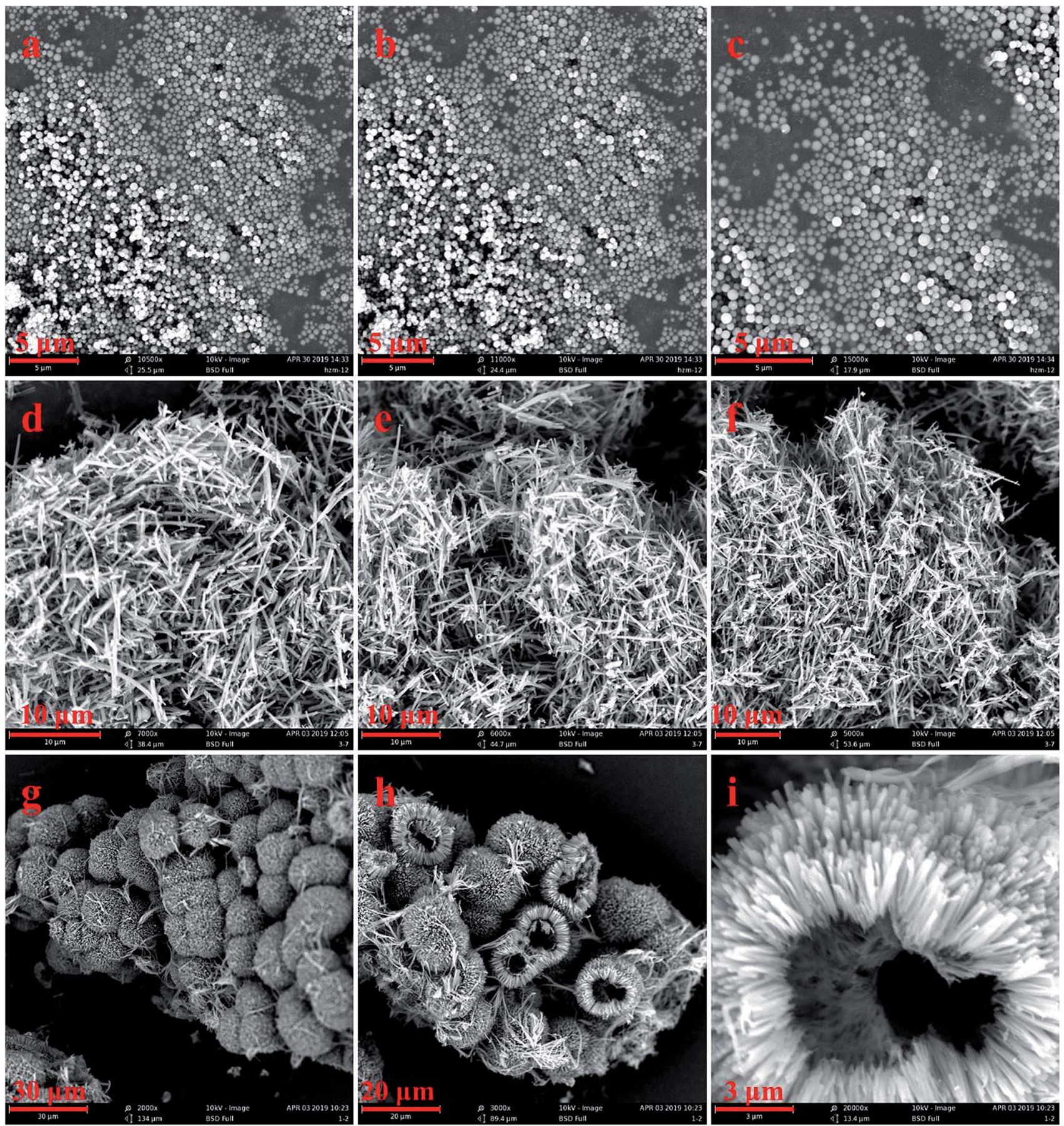

Fig. 3 SEM images of $(a-c) 1 Z n\left(D M F, 100{ }^{\circ} \mathrm{C}, 0.1 \mathrm{~g} \mathrm{PVP}\right)$; $(\mathrm{d}-\mathrm{f}) 2 \mathrm{Zn}\left(\mathrm{MeOH}, 120^{\circ} \mathrm{C}\right) ;(\mathrm{g}-\mathrm{i}) 3 \mathrm{Zn}(0.1 \mathrm{mmol} \mathrm{NaAC}, 0.5 \mathrm{~h}$ of ultrasonic treatment, standing at room temperature for $24 \mathrm{~h}$ ).

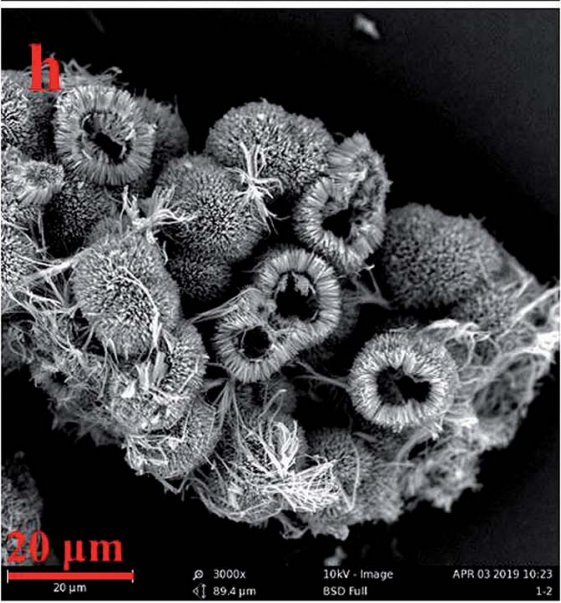

reaction, respectively, but $3 \mathrm{Zn}$ could reach more than $88 \%$. After controlling the morphology, the order of catalytic performance was still $\mathbf{1 Z n}<\mathbf{2 Z n}<\mathbf{3 Z n}$, which may be related to the structure of the MOFs. 3Zn with its 3D coordination structure may be more conducive to providing a smooth path for the rapid transfer of electrons.

Moreover, after adjusting the morphology, the catalytic effects of $\mathbf{1 Z n}, \mathbf{2 Z n}, \mathbf{3 Z n}$ were improved. The conversion of benzaldehyde was increased to $86 \%$ for the $1 \mathrm{Zn}$ nanosphere, $87 \%$ for the $2 Z n$ microstick and $90 \%$ for the $3 \mathbf{Z n}$ hollowsphere (Fig. S13†). The catalytic activity of all the Zn-MOFs may be related to the size, dispersion and accessible surface areas of the catalyst. ${ }^{36}$ For contrast, we studied the Knoevenagel condensation reaction with $n$-heptanal, keeping other conditions unchanged. The results are shown in the ESI (Fig. S14†). It was found that the results obtained with 


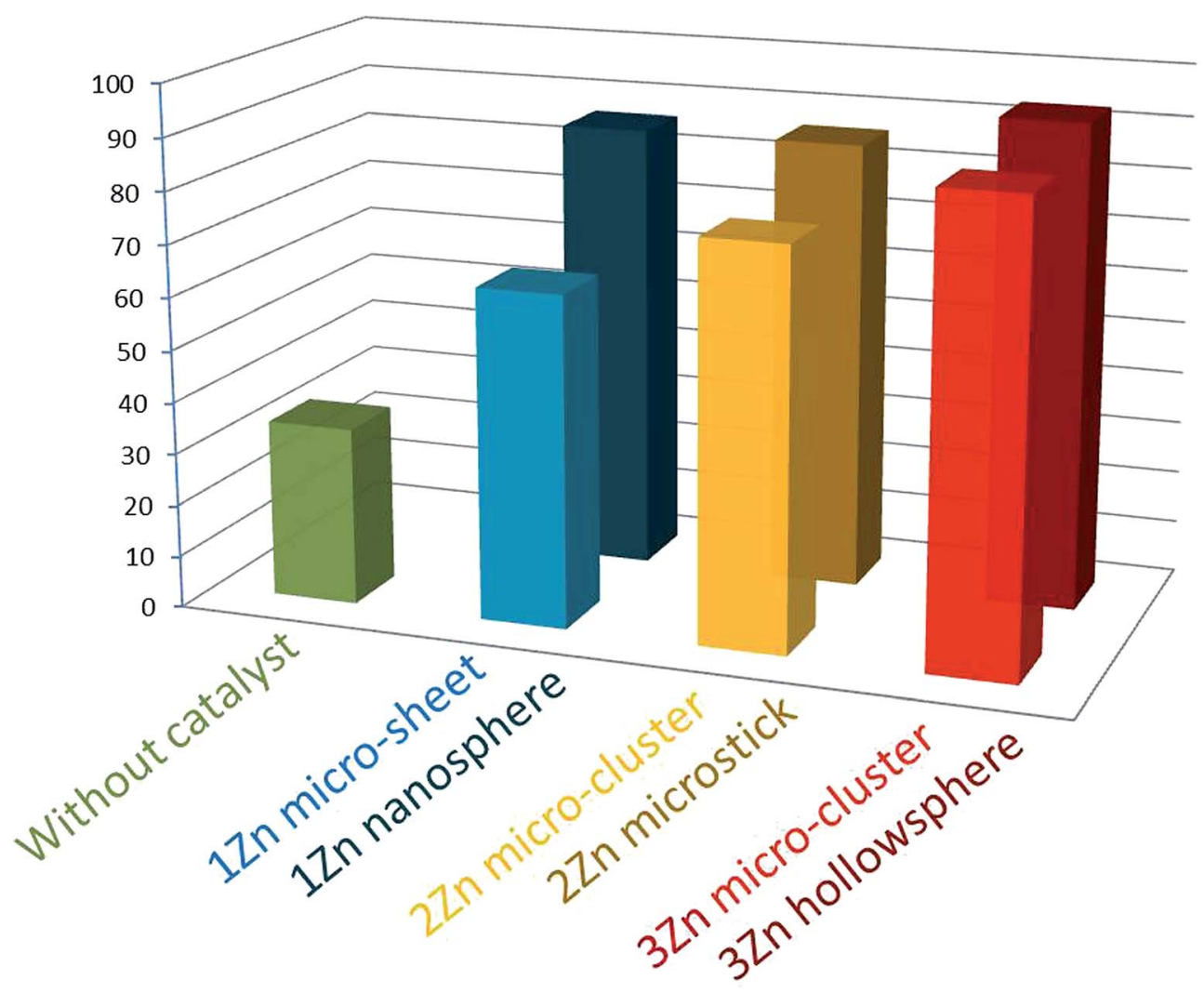

Fig. 4 The catalysts and their conversion in Knoevengal condensation reaction.

benzaldehyde or heptanal were similar in general; after adjusting the morphology, the conversion of heptanal catalyzed by the $1 \mathrm{Zn}$ nanosphere, the $\mathbf{2 Z n}$ microstick and the $\mathbf{3 Z n}$ hollowsphere were still higher than those of their microcrystals. The catalytic efficiency of the $1 \mathbf{Z n}$ nanosphere reached $90 \%$, while that of the $3 \mathrm{Zn}$ hollowsphere was $85 \%$, close to that of the $3 \mathbf{Z n}$ micro-cluster. On this basis, we performed the BET analysis of the $\mathbf{3 Z n}$ micro-cluster and $\mathbf{3 Z n}$ hollowsphere, and the results presented in the ESI (Fig. S12 $\dagger$ ) show that the median pore width of the $3 \mathbf{Z n}$ micro-cluster and 3Zn hollowsphere are similar. The BET surface area of the micro-cluster is larger than that of the hollowsphere, but the volume of the pores is smaller than that of the hollowsphere. So, we suppose that because of the similar pore width, the key to improving the conversion of benzaldehyde is the pore volume. However, in comparison, heptanal is bulky and cannot enter the pore as easily as benzaldehyde, so the catalytic efficiency of the $\mathbf{3 Z n}$ hollowsphere is close to that of the 3Zn micro-cluster. ${ }^{31,37,38}$ The XRD patterns of all the catalysts after catalysis were consistent with those before catalysis (Fig. S4-S9†), indicating that the structure did not change.

There are two main mechanisms of Knoevenagel condensation catalyzed by MOFs: basic catalysis and bifunctional acid-base catalysis. ${ }^{39}$ In our study, the three $\mathrm{Zn}$ MOFs seemed to prefer the acid-catalyzed mechanism since they did not have a strong basic group, such as the amino group; although the ligand contains two $\mathrm{N}$ atoms, these two $\mathrm{N}$ atoms already have three bonds, the electron cloud is dispersed, and the $-\mathrm{NO}_{2}$ and $-\mathrm{COOH}$ groups on the organic carboxylic acid ligands also weaken the basicity. Based on other studies, ${ }^{36,40,41}$ we proposed a possible bifunctional acid-base catalytic mechanism. The Zn(II) in the Zn-MOF has empty atomic orbitals, which can be used as the Lewis acid sites. The carbonyl oxygen carries a pair of lone pair electrons that coordinate with $\mathrm{Zn}(\mathrm{II})$, so the positive charge on the $\mathrm{O}$ atom can promote further polarization of the carbonyl group. The positive electricity of the carbonyl $\mathrm{C}$ atom can thereby be enhanced. At the same time, the hydroxyl $\mathrm{O}$ atom coordinated with the Zn(II) ion acted as the center of the Lewis basic sites, which promoted the active methylene of malonitrile to remove protons and formed a carbon anion near benzaldehyde. Then, malonitrile attacked the carbonyl $\mathrm{C}$ atom of benzaldehyde, and the intermediate became the product and regenerated the catalyst after rearrangement and dehydration (Fig. 5).

\section{Conclusions}

In summary, three kinds of novel Zn-MOFs were synthesized, and their coordination directions were affected by different ligands, resulting in the formation of $1 \mathrm{D}, 2 \mathrm{D}$ and $3 \mathrm{D}$ structures. By changing the reaction conditions, the crystal reassembly was affected, and its morphology could be regulated. 
<smiles>O=Cc1ccccc1</smiles><smiles>N#CCC#N</smiles>
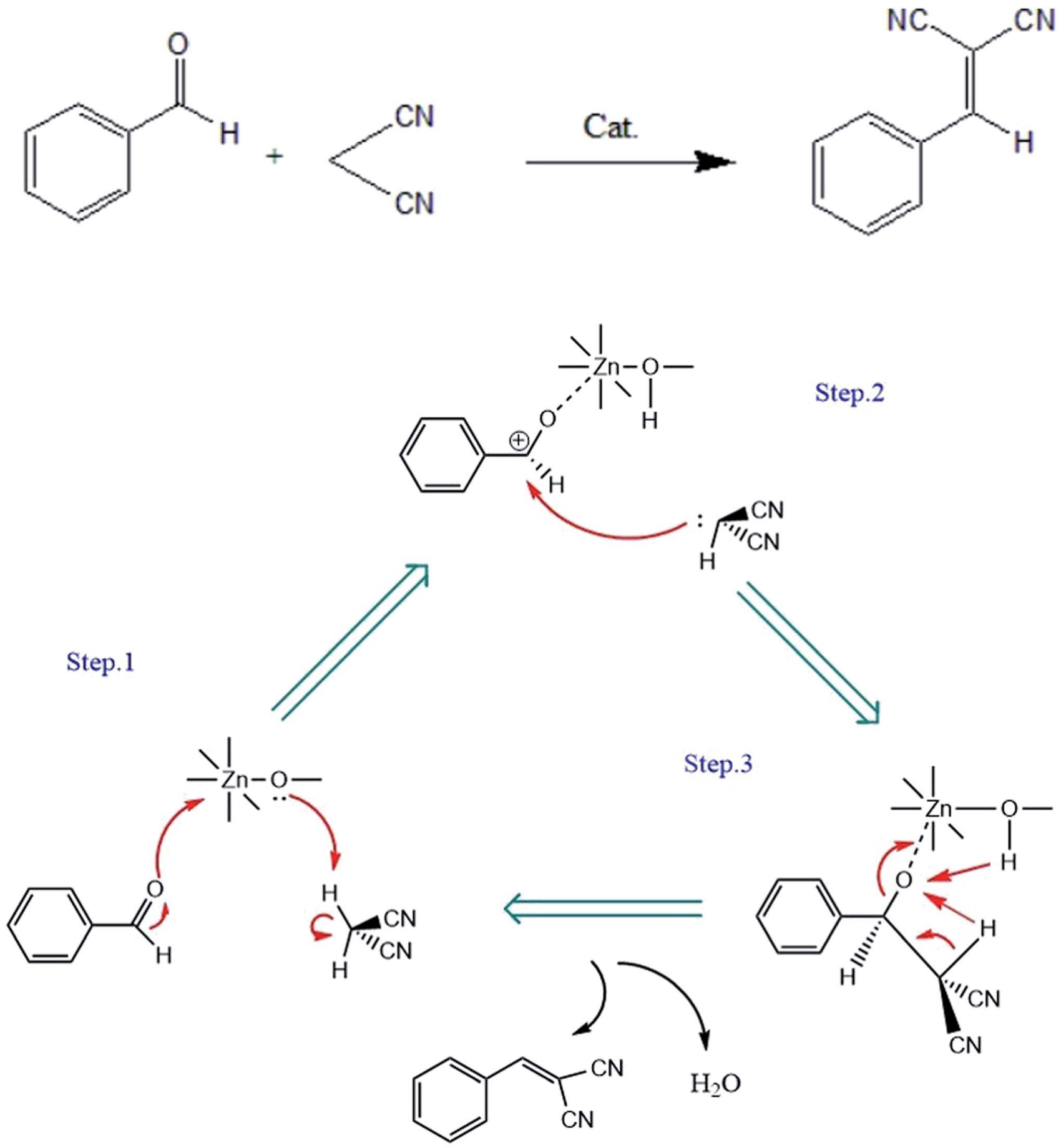

Fig. 5 The scheme catalytic mechanism of Knoevengal condensation reaction.

Finally, 1Zn micro-sheet, 1Zn nanospheres, 2Zn microflower, 2Zn micro-stick, 3Zn micro-flower, and 3Zn hollowspheres were obtained. The catalytic properties of all of these catalysts for the Knoevenagel condensation reaction were explored. The selectivity of all catalysts was $100 \%$, among which the benzaldehyde conversion rate of $3 \mathbf{Z n}$ hollowspheres was the highest, reaching a peak of $90 \%$. We believe that the work in this paper, especially the control of the crystal growth direction and reassembly mode, can provide a reference for the design of crystals with special morphologies to meet different needs.

\section{Author contributions}

The manuscript was written through contributions of all authors. All authors have given approval to the final version of the manuscript. 


\section{Conflicts of interest}

There are no conflicts to declare.

\section{Acknowledgements}

We gratefully acknowledge the financial support from the National Natural Science Foundation of China (No. 21371058) and University Student Research Plan (USRP) of ECUST.

\section{Notes and references}

1 M. D. Allendorf, R. J. T. Houk, L. Andruszkiewicz, A. A. Talin, J. Pikarsky, A. Choudhury, K. A. Gall and P. J. Hesketh, J. Am. Chem. Soc., 2008, 130, 14404-14405.

2 A. Schneemann, V. Bon, I. Schwedler, I. Senkovska, S. Kaskel and R. A. Fischer, Chem. Soc. Rev., 2014, 43, 6062-6096.

3 H. Zeng, M. Xie, Y. L. Huang, Y. F. Zhao, X. J. Xie, J. P. Bai, M. Y. Wan, R. Krishna, W. G. Lu and D. Li, Angew. Chem., Int. Ed., 2019, 58, 8515-8519.

4 M. Li, D. Li, M. O'Keeffe and O. M. Yaghi, Chem. Rev., 2014, 114, 1343-1370.

5 O. M. Yaghi and H. Li, J. Am. Chem. Soc., 1995, 117, 10401-10402. 6 H. Li, M. Eddaoudi, T. L. Groy and O. M. Yaghi, J. Am. Chem. Soc., 1998, 120, 8571-8572.

7 H. Li, M. Eddaoudi, M. O'Keeffe and O. M. Yaghi, Nature, 1999, 402, 276-279.

8 J. R. Li, R. J. Kuppler and H. C. Zhou, Chem. Soc. Rev., 2009, 38, 1477-1504.

9 T. Rodenas, I. Luz, G. Prieto, B. Seoane, H. Miro, A. Corma, F. Kapteijn, F. Xamena and J. Gascon, Nat. Mater., 2015, 14, 48-55.

10 A. Cadiau, K. Adil, P. M. Bhatt, Y. Belmabkhout and M. Eddaoudi, Science, 2016, 353, 137-140.

11 H. Kim, S. Yang, S. R. Rao, S. Narayanan, E. A. Kapustin, H. Furukawa, A. S. Umans, O. M. Yaghi and E. N. Wang, Science, 2017, 356, 430-432.

12 W. Xia, A. Mahmood, R. Q. Zou and Q. Xu, Energy Environ. Sci., 2015, 8, 1837-1866.

13 S. L. Zhao, Y. Wang, J. C. Dong, C. T. He, H. J. Yin, P. F. An, K. Zhao, X. F. Zhang, C. Gao, L. J. Zhang, J. W. Lv, J. X. Wang, J. Q. Zhang, A. M. Khattak, N. A. Khan, Z. X. Wei, J. Zhang, S. Q. Liu, H. J. Zhao and Z. Y. Tang, Nat. Energy, 2016, 1, 1-10.

14 D. Sheberla, J. C. Bachman, J. S. Elias, C. J. Sun, Y. Shao-Horn and M. Dinca, Nat. Mater., 2017, 16, 220-224.

15 J. Lee, O. K. Farha, J. Roberts, K. A. Scheidt, S. T. Nguyen and J. T. Hupp, Chem. Soc. Rev., 2009, 38, 1450-1459.

16 H. Q. Xu, J. H. Hu, D. K. Wang, Z. H. Li, Q. Zhang, Y. Luo, S. H. Yu and H. L. Jiang, J. Am. Chem. Soc., 2015, 137, 13440-13443.

17 M. T. Zhao, K. Yuan, Y. Wang, G. D. Li, J. Guo, L. Gu, W. P. Hu, H. J. Zhao and Z. Y. Tang, Nature, 2016, 539, 76-80.

18 M. D. Allendorf, C. A. Bauer, R. K. Bhakta and R. J. T. Houk, Chem. Soc. Rev., 2009, 38, 1330-1352.
19 Y. J. Cui, R. J. Song, J. C. Yu, M. Liu, Z. Q. Wang, C. D. Wu, Y. Yang, Z. Y. Wang, B. L. Chen and G. D. Qian, Adv. Mater., 2015, 27, 1420-1425.

20 S. Y. Wu, Y. N. Lin, J. W. Liu, W. Shi, G. M. Yang and P. Cheng, Adv. Funct. Mater., 2018, 28, 10.

21 Q. H. Yang, Q. Xu and H. L. Jiang, Chem. Soc. Rev., 2017, 46, 4774-4808.

22 Y. Hayashi, Y. Miyamoto and M. Shoji, Tetrahedron Lett., 2002, 43, 4079-4082.

23 P. B. Mills, E. Struys, C. Jakobs, B. Plecko, P. Baxter, M. Baumgartner, M. Willemsen, H. Omran, U. Tacke, B. Uhlenberg, B. Weschke and P. T. Clayton, Nat. Med., 2006, 12, 307-309.

24 Y. J. Bian, Y. Qin, L. W. Xiao and J. T. Li, Chin. J. Org. Chem., 2006, 26, 1165-1172.

25 G. Kaupp, M. R. Naimi-Jamal and J. Schmeyers, Tetrahedron, 2003, 59, 3753-3760.

26 P. Lidstrom, J. Tierney, B. Wathey and J. Westman, Tetrahedron, 2001, 57, 9225-9283.

27 A. Lee, A. Michrowska, S. Sulzer-Mosse and B. List, Angew Chem. Int. Ed. Engl., 2011, 50, 1707-1710.

28 X. Y. Li, B. N. Lin, H. B. Li, Q. Yu, Y. Ge, X. Jin, X. H. Liu, Y. H. Zhou and J. P. Xiao, Appl. Catal. B-Environ., 2018, 239, 254-259.

29 N. Yao, J. Tan, Y. Liu and Y. L. Hu, Synlett, 2019, 30, 699-702. 30 L. Zhu, X. Q. Liu, H. L. Jiang and L. B. Sun, Chem. Rev., 2017, 117, 8129-8176.

31 J. Gascon, U. Aktay, M. D. Hernandez-Alonso, G. P. M. van Klink and F. Kapteijn, J. Catal., 2009, 261, 75-87.

32 A. H. Chughtai, N. Ahmad, H. A. Younus, A. Laypkov and F. Verpoort, Chem. Soc. Rev., 2015, 44, 6804-6849.

33 U. P. N. Tran, K. K. A. Le and N. T. S. Phan, ACS Catal., 2011, 1, 120-127.

34 X. Cai, J. Lin and M. Pang, Cryst. Growth Des., 2016, 16, 35653568.

35 H. Guo, Y. Zhu, S. Wang, S. Su, L. Zhou and H. Zhang, Chem. Mater., 2012, 24, 444-450.

36 J. J. Wang, X. X. Wang, H. T. Xu, X. Zhao, Z. Z. Zheng and Z. L. Xu, ChemPlusChem, 2017, 82, 1182-1187.

37 S. Hasegawa, S. Horike, R. Matsuda, S. Furukawa, K. Mochizuki, Y. Kinoshita and S. Kitagawa, J. Am. Chem. Soc., 2007, 129, 2607-2614.

38 Y. K. Hwang, D. Y. Hong, J. S. Chang, S. H. Jhung, Y. K. Seo, J. Kim, A. Vimont, M. Daturi, C. Serre and G. Ferey, Angew. Chem. Int. Ed., 2008, 47, 4144-4148.

39 Y. Yang, H. F. Yao, F. G. Xi and E. Q. Gao, J. Mol. Catal. A: Chem., 2014, 390, 198-205.

40 V. N. Panchenko, M. M. Matrosova, J. Jeon, J. W. Jun, M. N. Timofeeva and S. H. Jhung, J. Catal., 2014, 316, 251259.

41 Y. Y. Li, Y. Q. Su, J. Xu, Z. L. Xu and H. T. Xu, Bull. Chem. Soc. Jpn., 2017, 90, 1152-1156. 